\title{
Trajetórias de mulheres no esporte em Portugal: assimetrias, resistências e possibilidades
}

\author{
Angelita Alice Jaeger* \\ Paula Botelho Gomes** \\ Paula Silva*** \\ Silvana Vilodre Goellner ${ }^{* * * *}$
}

\begin{abstract}
Resumo: Fundamentada no aporte teórico dos estudos de gênero, esta pesquisa efetivou-se através da realização de entrevistas com 21 mulheres atletas e ex-atletas atuantes nas funções técnicas e diretivas no esporte de Portugal. Emergiram três unidades de significados cuja análise permite identificar avanços na ampliação da participação das mulheres no campo esportivo, ainda que, para que se mantenha, seja necessário que as mulheres diversifiquem funções e aceitem condições de trabalho diferenciadas daquelas oferecidas aos homens. Rejeitando a posição de vítimas, as entrevistadas transformam as assimetrias em desafios e sugerem ações para incentivar, ampliar e consolidar a participação feminina em todas as esferas de competência esportiva.
\end{abstract}

Palavras-chave: Mulheres. Esporte. Identidade de gênero. Trabalho feminino.

\section{CoNSIDERAÇõES INICIAIS}

O ano de 2007 foi designado pelo Parlamento Europeu e pelo Conselho da União Europeia (UE) como o "Ano Europeu da Igualdade de Oportunidades para Todos". ${ }^{1}$ Considerando a multiplicidade de cul-

\footnotetext{
* Professora Doutora do Centro de Educação Física e Desportos da Universidade Federal de Santa Maria. Santa Maria, RS, Brasil. E-mail: ajaeger@smail.ufsm.br

** Professora Doutora da Faculdade de Ciências do Desporto da Universidade do Porto. Porto, Portugal. E-mail: botgomes@fade.up.pt

*** Professora Doutora da Faculdade de Ciências do Desporto da Universidade do Porto. Porto, Portugal. E-mail: psilva@fade.up.pt

**** Professora Doutora da Escola de Educação Física da Universidade Federal do Rio Grande do Sul. Porto Alegre, RS, Brasil. E-mail: goellner@terra.com.br

1 Decisão n. 771/2006/CE do Parlamento Europeu e do Conselho, em 16 de maio de 2006, instituindo 2007 como o Ano Europeu da Igualdade de Oportunidades para Todos (2007). Disponivel em: <http://eur-lex.europa.eu/smartapi/cgi/sga_doc?smartapi!celexplus!prod!Doc Number\&lg=pt\&type_doc=Decision\&an_doc=2006\&nu_doc=771> Acesso em: 24 abr. 2007.
} 
turas da UE, foram propostas várias ações com o intuito de criar condições para construir uma sociedade mais igualitária. Em Portugal, esse tema tem sido pauta de agendas governamentais há mais de uma década. Com o objetivo de minimizar as desigualdades na sociedade portuguesa, em 1997, elaborou-se o "Plano Global para a Igualdade de Oportunidades" e, em decorrência deste, em 1998, criou-se a Comissão para Igualdade e para os Direitos das Mulheres. No ano de 2003, foi lançado o II Plano Nacional para a Igualdade, ${ }^{2}$ e, em março de 2007, o Conselho de Ministros determinou a elaboração de um novo conjunto de ações, composto pelos III Plano Nacional para a Igualdade de Gênero, III Plano Nacional contra a Violência Doméstica e I Plano Nacional contra o Tráfico de Seres Humanos.

Não se pode negar que essas ações se constituem em avanços para uma maior democratização da sociedade portuguesa. Todavia, segundo Pinto (2007), face aos demais países da UE, Portugal continua num nível inicial de investimentos no que tange a projetos para promover a igualdade de oportunidades, reduzindo a sua ação à elaboração de leis, o que não assegura a operacionalização das mudanças necessárias na histórica assimetria entre homens e mulheres.

Essas assimetrias são apontadas e estudadas em diferentes instâncias sociais. O esporte constitui-se em um dos espaços onde as desigualdades entre homens e mulheres continuam acentuadas. Em função disso, há seis décadas, pode-se registrar, em âmbito internacional, a promoção de conferências, debates e encontros ${ }^{3}$ que discutem a situação das mulheres no esporte. Tais discussões resultaram na produção de documentos ${ }^{4}$ que incentivam a elaboração e a operaciona-

\footnotetext{
2 Disponível em: <http://cidm.madbug.com/?TopLevellD=7>. Acesso em: 25 abr. 2007.

${ }^{3}$ Exemplos: Congressos da Associação Internacional de Educação Física e Desporto para Raparigas e Mulheres; Conferências Mundiais da ONU sobre/para as Mulheres; Conferência Árabe sobre Mulheres e Desporto; Conferências Internacionais Mulheres e Desporto; Congresso Pan-americano de Educação Física, Desporto e Recreação para a Mulher; entre outros/as (CARVALHO; CRUZ, 2007).

${ }^{4}$ Exemplos: Carta Europeia do Desporto para Todos (1976); Carta Internacional da Educação Física e do Desporto (1978); Conselho Europeu - Resolução sobre a maior participação das mulheres no desporto (1981); União Europeia - Resolução do Parlamento Europeu sobre a Mulher e o Desporto (1987); Declaração de Brighton (1994); Declaração e Plataforma de Ação de Pequim; Resolução da $1^{\text {a }}$ Conferência Mundial do Comitê Olímpico Internacional sobre Mulheres e Desporto (1996) Resolução europeia sobre a prevenção do assédio e abuso sexual sobre mulheres, jovens e crianças no desporto (2000); Recomendação 1701 - Discriminação sobre as mulheres e raparigas nas atividades desportivas (2005), entre outros (CARVALHO; CRUZ, 2007).
}

Movimento, Porto Alegre, v. 16, n. 01, p. 245-267, janeiro/março de 2010. 
lização de estratégias para eliminar as diferenças entre homens e mulheres no acesso ao esporte, ampliando a inserção e a participação destas nos diferentes espaços e funções que o estruturam, seja no âmbito do lazer, seja no da educação ou do alto nível. Entre esses documentos, a Declaração de Brighton, ${ }^{5}$ elaborada em 1994, figurou como um dos mais importantes, visto que estimulava a correção de distorções no esporte por meio de ações que incentivassem o aumento da participação das mulheres em todos os "níveis, funções e esferas de competência". O Comitê Olímpico Internacional (COI), ao tomar conhecimento dessa Declaração, decidiu, nesse mesmo ano, que um dos objetivos de todas as instituições que atuavam sob as suas normativas deveria ser compor seus órgãos executivos com, pelo menos, $10 \%$ de mulheres até o ano 2000 e $20 \%$ até o ano 2005. Decidiu, ainda, realizar a Conferência Mundial Mulheres e Desporto a cada quatro anos, com o intuito de acompanhar o desenvolvimento de ações nesse sentido, estabelecendo metas centralizadas na "melhoria da situação das mulheres no desporto", ampliando o seu campo de atuação e possibilitando que as mulheres elevassem seus níveis de intervenção (CARVALHO; CRUZ, 2007).

Ainda que essa tenha sido uma ação propositiva de grande importância, pouco ou quase nada se fez em Portugal, pois o Comitê Olímpico do país nem sequer acolheu as recomendações do COI (CRUZ, 2001). Resultados pouco animadores também são observados em pesquisas, que assinalam que, em Portugal, as mulheres estão sub-representadas no esporte, são pouco incentivadas a praticá-lo e a permanecer na área, recebem premiações inferiores às dos homens e têm pouco acesso aos cargos diretivos e espaços reduzidos na mídia (MARIVOÉT, 2001, 2003; SILVA; CARVALHO, 2001; SANTOS, 2001; RIBEIRO, 2006, CRUZ, 2007). No contexto dos Jogos Olímpicos Modernos, a participação de atletas portuguesas não expressou significativo aumento. Em Barcelona (1996), participaram 24 atletas; em Sidney (2000), 13; em Atenas (2004), 17. Esse cenário parece não se

\footnotetext{
${ }^{5}$ A Declaração de Brighton foi aprovada pelas/os 280 delegadas/os de 82 países representando organizações governamentais e não-governamentais, comitês olímpicos nacionais, federações nacionais e internacionais e instituições de ensino e de investigação de todo o mundo (CARVALHO; CRUZ, 2007).
}

Movimento, Porto Alegre, v. 16, n. 01, p. 245-267, janeiro/março de 2010. 
alterar para 2008 (Pequim). Segundo Cruz, Silva e Botelho (2006), os novos projetos "Pequim 2008" e "Esperanças Olímpicas" pouco acenam para grandes transformações no esporte de Portugal. Além disso, o país figura na comunidade europeia como a nação que apresenta " $\mathrm{o}$ menor índice de participação feminina no desporto, quer como praticante quer no nível de decisão" (GRAÇA, 2006, p. 12).

Considerando-se esses dados, é possível verificar que a situação das mulheres no esporte português emerge como um espaço generificado no que tange ao acesso e à permanência no esporte, seja como atletas, seja no domínio da gestão. Assumimos as palavras de Hall (1990), quando diz que o esporte é historicamente produzido, socialmente construído e culturalmente definido, por isso mesmo é um lugar que pode ser transformado. Nessa perspectiva, argumentamos que as ações individuais de muitas esportistas, os movimentos de mulheres e as estudiosas do feminismo têm denunciado, questionado e sacudido o domínio masculino no esporte. Esse conjunto múltiplo de ações está, pouco a pouco, transformando as relações de gênero nesse contexto.

Considerando que o esporte é um lugar privilegiado para perscrutar as relações de gênero, esta pesquisa objetiva analisar as condições de atuação de mulheres atletas e ex-atletas que ocupam funções técnicas e diretivas no esporte em Portugal. Essa temática justifica-se: a) pela carência de pesquisas sobre essa temática em Portugal; b) pelo amplo conjunto de resoluções e recomendações que incidem sobre o esporte nesse país; c) pelas dificuldades das instituições governamentais em operacionalizar ações que busquem acabar com as desigualdades de gênero no esporte; d) pela percepção de que, apesar de todos esses entraves, as mulheres borram fronteiras, transpõem barreiras, enfrentam desafios e lutam para ampliar a sua participação nos diferentes níveis, esferas e funções esportivas.

\section{DeCISÕes METOdológICAS}

Esta investigação caracteriza-se como qualitativa, visto que "permite ao investigador a descrição e interpretação das representações e dos significados que um grupo social dá à sua experiência cotidiana" (MOLINA NETO, 1999, p. 12). Para colher as informações, optamos

Movimento, Porto Alegre, v. 16, n. 01, p. 245-267, janeiro/março de 2010. 
pela entrevista semiestruturada, ${ }^{6}$ por ser esse um instrumento que possibilitou conhecer os aspectos da vida privada e profissional das mulheres investigadas. A entrevista foi organizada a partir de um roteiro de tópicos na forma de um guia de frases que foram tomadas como lembretes, objetivando monitorar o desenvolvimento da entrevista (GASKELL, 2000). Essa flexibilidade no roteiro permitiu que as entrevistadas ${ }^{7} \mathrm{e}$ as pesquisadoras pudessem melhor explorar os temas que emergiam no decorrer das entrevistas, sem, no entanto, perder o seu foco. Todas as entrevistas foram realizadas face a face, após consentimento informado, sendo gravadas e, posteriormente, transcritas em um registro informático.

Considerando-se o objetivo desta investigação, foram selecionadas 21 mulheres $^{8}$ que estavam atuando no esporte em Portugal nas funções de treinadora, coordenadora esportiva, árbitra, oficial de mesa, dirigente e diretora técnica.

Para sistematizar o material empírico, foi utilizado o programa QSRNvivo, o qual auxilia na organização e arquivamento de textos, mas que não pode ser confundido com um instrumento de análise de dados, conforme adverte Kelle (2000). Mergulhamos no material colhido, buscando atribuir-lhe sentido, como sugere Patton (2002). Na leitura e análise das entrevistas, percebeu-se que alguns temas eram recorrentes; estes se constituíram como unidades de análise. Resumidas em pequenas frases, essas unidades expressaram o foco sobre o qual foram organizadas as falas das mulheres entrevistadas. Três eixos destacaram-se: a) os múltiplos percursos das mulheres no esporte; b) as assimetrias e os obstáculos vividos pelas mulheres no esporte; c) as resistências e as sugestões das mulheres para as melhorias no esporte em Portugal.

\footnotetext{
${ }^{6}$ Segundo Trivinos (1987, p. 146), por entrevista semiestruturada entende-se, em geral, aquela "que parte de certos questionamentos básicos, apoiados em teorias e hipóteses que interessam à pesquisa e que, em seguida, oferecem amplo campo de interrogativas, fruto de novas hipóteses que vão surgindo à medida que se recebem respostas dos informantes".

${ }^{7}$ A identidade das entrevistadas foi preservada; no entanto, as participantes são identificadas no texto a partir de sua função no esporte português.

${ }^{8}$ Essas mulheres participaram de um projeto intitulado "Agir para Mudar", realizado pela Associação Portuguesa Mulheres e Desporto (APMD), financiado pelo Fundo Social Europeu. Disponível em: www.mulheresdesporto.org.pt

Movimento, Porto Alegre, v. 16, n. 01, p. 245-267, janeiro/março de 2010.
} 
Nos caminhos trilhados durante as análises das fontes empíricas, esses temas atravessam-se mutuamente, como "[...] se houvesse uma passagem de um termo por dentro do outro, passando pelos poros do outro, cada qual reenviando ao outro sem cessar" (CHAUÍ, 2002 apud FISCHER, 2005, p.138), produzindo a emergência das unidades de análise e seus desdobramentos.

\section{Os MÚLTIPLOS PERCURSOS DE MULHERES NO ESPORTE EM PORTUGAL}

A primeira categoria que emergiu da análise das entrevistas constituiu-se em torno das múltiplas vivências que as mulheres acumularam em anos de inserção no esporte. Os percursos que trilharam são diversificados e variam, tanto no que se refere às diferentes práticas corporais e esportivas vivenciadas quanto nas posições e funções ocupadas por cada uma delas no âmbito da organização esportiva. Essa multiplicidade explícita de percursos assinala que o investimento no esporte não é construído somente por vitórias, sucessos, fama e dinheiro, principalmente para as mulheres. Elas precisam criar alternativas para enfrentar as dificuldades de modalidades nem sempre valorizadas, incorporar as mudanças, conviver com a falta de investimentos e aprender a negociar a sua permanência no interior de um campo fecundo de contradições.

As entrevistas apontam que muitas dessas mulheres viveram diversas e diferentes inconstâncias, dúvidas e barreiras no esporte. Todas mencionam a inserção nas práticas corporais e esportivas a partir da identificação com alguma modalidade em especial, o que podia acontecer tanto na escola quanto em clubes esportivos, geralmente frequentados pelos familiares. Essas mulheres, ainda meninas, circularam entre modalidades e/ou clubes até atingirem resultados que lhes asseguraram uma maior permanência em um determinado lugar e/ou modalidade. Nesse sentido, suas vivências no esporte são plurais e muitas delas investiram em mais de uma modalidade esportiva na trajetória de atletas. Essas mulheres são ex-atletas ou estão competindo no handebol, wakebord, judô, ginástica artística, atletismo, basquetebol, hóquei sobre patins, futsal e natação. Algumas chegaram aos níveis olímpicos, outras disputaram jogos ou continuam a fazê-lo em competições de nível internacional, nacional e regional.

Movimento, Porto Alegre, v. 16, n. 01, p. 245-267, janeiro/março de 2010. 
A instabilidade profissional da vida das atletas emergiu em diferentes lugares e falas; tal instabilidade aumentou a circulação dessas mulheres em diferentes clubes no esporte de alto rendimento. Algumas delas perderam seus espaços de treinamento porque os diretores das instituições decidiram fechar as portas do clube, acabar com a modalidade feminina para investir na masculina ou, ainda, preferiram investir em outro esporte que, naquele momento, fosse mais rentável.

Entre as diferentes dificuldades relatadas pelas entrevistadas, a necessidade de trabalhar para manter os seus gastos de treinamento foi a mais rememorada, pois exigia delas um investimento de tempo e dedicação em outras áreas e funções no esporte, além dos treinamentos junto às suas equipes. Muitas delas não conseguiam cobrir os seus gastos com o que ganhavam competindo, por isso trabalhavam para ter condições financeiras mínimas para continuar com os treinamentos, pagar deslocamentos, adquirir artigos esportivos e também cobrir gastos próprios com a sobrevivência. Essa situação é observada tanto nas entrevistas das ex-atletas quanto nas falas daquelas que estão hoje competindo. Algumas delas narram que assumiam diferentes funções esportivas, treinavam equipes infantis masculinas e femininas, arbitravam jogos, organizavam competições, ministravam aulas em escolas, entre outras tantas possibilidades, para melhorar as condições salariais. Essa situação parece ser diferente da experimentada pelos treinadores homens. Conforme uma das entrevistadas:

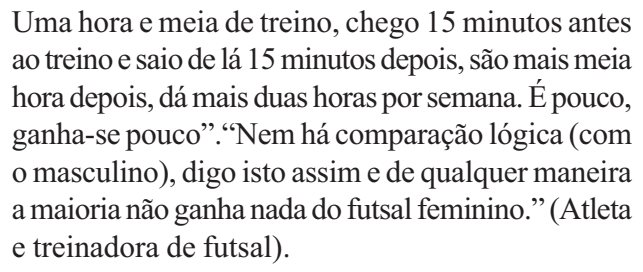
ao treino e saio de lá 15 minutos depois, são mais meia hora depois, dá mais duas horas por semana. É pouco, ganha-se pouco"."Nem há comparação lógica (com o masculino), digo isto assim e de qualquer maneira a maioria não ganha nada do futsal feminino." (Atleta e treinadora de futsal).

É essa interação entre as atividades esportivas e as demais funções exercidas no esporte que abre caminho para que as mulheres continuem atuando nesse campo. As entrevistas apontam que a permanência daquelas mulheres no cenário esportivo foi construída em meio a muitos atravessamentos e mudanças de direção. Sobretudo, a familiaridade e o gosto pela prática esportiva foram os elementos decisivos para a continuidade das suas ligações com o esporte.

Movimento, Porto Alegre, v. 16, n. 01, p. 245-267, janeiro/março de 2010. 
Quando focalizamos as modalidades e as funções desenvolvidas nesse campo, observamos que, na maior parte dos casos, não há uma linearidade entre a vida de atleta e a carreira profissional das mulheres entrevistadas. Em outras palavras, dificilmente elas são ex-atletas de uma modalidade e depois treinadoras ou dirigentes dessa mesma prática esportiva. O que vemos, por exemplo, são: ex-atleta de handebol e treinadora de futebol; atleta de wakebord e treinadora e coordenadora de rugby; ex-atleta de atletismo e dirigente de natação etc. Esses deslocamentos entre modalidades e/ou funções marcam profundamente a atuação profissional de mulheres no esporte em Portugal.

Isabel Cruz (2001) destaca que, apesar das constantes pressões empreendidas pela Associação Portuguesa Mulheres e Desporto sobre o governo português, as dificuldades apontadas pelas mulheres no esporte são as mesmas de décadas atrás. A falta de investimentos no esporte, a ausência de reconhecimento e visibilidade e, ainda, situações de desigualdades entre as mulheres e os homens continuam a marcar acentuadamente o esporte de Portugal - situações evidenciadas também por esta investigação. Tal realidade aponta para a compreensão de que essas dificuldades não são momentâneas, mas acompanham as trajetórias das entrevistadas. Vejamos alguns exemplos:

\begin{abstract}
Iniciei com 10 anos no tênis, disseram-me que por ser rapariga não podia praticar tênis porque não tinha possibilidades... Então decidi ir para o basquetebol. Disseram que não tinha grandes hipóteses por ser mulher, na altura andava com mais dois rapazes e eles ficaram e eu vim-me embora. (Ex-atleta e treinadora de basquetebol).

Eu acho em termos de reconhecimento do trabalho, os homens, as instituições têm mais dificuldade, na distribuição de prêmios, de reconhecer que as mulheres fizeram um bom trabalho, até hoje ninguém reconheceu. AAssociação de Natação do Porto faz uma entrega de prémios todos os anos, nunca fomos contempladas com isso. (Ex-atleta de atletismo e dirigente de natação).
\end{abstract}

Ao decidir dar continuidade à sua vida profissional no esporte, as mulheres adentraram espaços em que os homens eram a maioria absoluta, derrubando barreiras e transpondo fronteiras culturalmente

Movimento, Porto Alegre, v. 16, n. 01, p. 245-267, janeiro/março de 2010. 
erguidas entre os sexos. Ser atleta, especialmente do futebol, do hóquei sobre patins e do judô, por exemplo, exigiu dessas mulheres mais do que a aprendizagem do gesto técnico - demandou certa desobediência e coragem para avançar alguns limites que foram historicamente determinados às mulheres, nesses e em tantos outros lugares, evidenciando que, apesar de difíceis de serem trilhados, esses caminhos são possíveis de serem transformados.

\section{DAS ASSIMETRIAS E DE OUTROS OBSTÁCULOS}

A análise das entrevistas permitiu verificar que, apesar de algumas mulheres terem longa história no esporte português, nenhuma delas ocupou posições de comando nos altos escalões do esporte nacional. Apenas duas assumiram o lugar de dirigente: uma exerceu o cargo de presidente de um clube de natação exclusivamente feminino e outra atuou como vice-dirigente em um clube misto de basquetebol.

Passada mais de uma década da Declaração de Brighton, parece que ainda está muito distante o alcance das metas estipuladas pelo COI para a participação das mulheres nos Comitês Olímpicos. Verificamos que, das 28 Federações ligadas ao Comitê Olímpico de Portugal, ${ }^{9}$ apenas duas são presididas por mulheres. Além dessas, ainda há 31 Federações não-Olímpicas e em apenas uma delas aparecem mulheres em cargos de gestão.

Essa situação não é exclusiva da sociedade portuguesa. Na Alemanha, Pfister e Radtke (2007) destacam que 96\% das presidências das Federações são conduzidos por homens, os quais também ocupam mais de $80 \%$ das posições importantes no esporte de alto nível e na estrutura financeira. Entre os aspectos que limitam a participação feminina na liderança de organizações esportivas, estão: a ausência de um estreito vínculo com o esporte, falta de prestígio profissional fora do esporte, família que não apoia o seu envolvimento com o esporte e, ainda, companheiro e filhos/as não-envolvidos com o campo esportivo. Esses aspectos guardam semelhanças e reforçam alguns dos motivos

${ }^{9}$ Dados disponíveis em: <http://www.comiteolimpicoportugal.pt/conteudo.php?page=federacoes>. Acesso em 12 nov. 2007.

Movimento, Porto Alegre, v. 16, n. 01, p. 245-267, janeiro/março de 2010. 
mencionados pelas entrevistadas quando falaram sobre as dificuldades que o envolvimento com o esporte produz em suas vidas.

\begin{abstract}
É muito difícil ser mulher, porque tem uma actividade normalmente laboral e tem filhos, a maior parte das vezes, e tem a vida de casa. Conseguir conciliar isto tudo é muito difícil, principalmente se o marido não estiver ligado ao desporto ou não estiver a exercer um cargo no desporto. (Ex-atleta de atletismo e dirigente de natação).

Acho estranho não só existirem poucas mulheres, mas também por haver poucas mulheres que se impõem e querem assumir este tipo de papel (dirigente de desporto). Eu acho que a nossa geração ainda não está preparada para assumir este cargo, por causa de nós vivermos ainda num mundo machista. (Ex-atleta de natação e dirigente de basquetebol).
\end{abstract}

Se, por um lado, a dificuldade de conciliar o esporte e a vida familiar é um obstáculo a ser transposto pelas mulheres, por outro lado, muitas vezes é a própria mulher que, diante das difíceis condições de atuação nesse campo e pressionada pelos tradicionais espaços que lhe são reservados, decide abandonar o esporte e investir em outra carreira profissional. Segundo Shaw (2007), no meio empresarial, as mulheres são apontadas como mais eficientes em trabalhos com práticas cooperativas e em consultorias e como hábeis em negociações; entretanto, essas potencialidades são desvalorizadas no âmbito da administração esportiva. Já a força, a agressão e a competição, que são associadas ao sucesso nas carreiras dos homens atletas, são tomadas como requisitos indispensáveis ao comando das organizações esportivas.

Não é somente nos altos postos da administração do esporte que as mulheres estão em número reduzido; na função de técnica também, seja em equipes masculinas, seja em femininas, principalmente no esporte de rendimento. Para Mourão (2003), a resistência masculina ao trabalho técnico da mulher, as viagens para participar em competições, os longos períodos de treinamento e a dificuldade em gerir o espaço doméstico são alguns dos elementos que influenciam no fato de a mulher não desejar "entrar no espaço competitivo de alta perfor-

Wovimento, Porto Alegre, v. 16, n. 01, p. 245-267, janeiro/março de 2010. 
mance". Fasting (2001) acredita que a existência de mais homens do que mulheres na função técnica acontece porque o sistema das relações sociais tradicionalmente construído ainda separa os trabalhos adequados aos homens e aqueles destinados às mulheres. Além disso, a representação do esporte como um território onde os homens produzem e demonstram a sua masculinidade favorece a percepção, facilmente identificada em nível de senso comum, de que treinadores geralmente são homens, o que acaba por produzir certos questionamentos acerca das competências das mulheres nessa posição. Narram as entrevistadas:

\footnotetext{
Houve um conflito que eu tive com um pai, que eu fiquei daquelas coisas que só passando pela situação, é que havia regras num treino que tinham que ser cumpridas. Ele insultou-me por eu ter feito aquilo..., depois disse que eu deveria era estar em casa a lavar louça e aquelas coisas. E eu ok, não lhe respondi. (Atleta e treinadora de futsal).

Pela experiência que eu tenho de já ter treinado, no início há aqueles risinhos e não sei quê, e apercebeste de certas coisas diferentes, "ah! uma rapariga!" e tentam dar-te a volta. Mas se tu também te conseguires impor, eles mudam logo. É mais fácil o homem fazer carreira do que a mulher no hóquei. (Atleta e treinadora de hóquei sobre patins).
}

Através desses depoimentos, é possível identificar que há uma acentuada dificuldade no acesso de mulheres ao trabalho técnico em esportes que, há muito tempo, pertencem à esfera masculina. De qualquer modo, tanto em esportes tradicionalmente representados como masculinos (futebol) quanto nos esportes tidos como femininos (ginástica artística), encontramos homens ocupando a posição de treinador da equipe ou de atletas principais. As treinadoras ocupam posições secundárias, ficando responsabilizadas pelas equipes infantis e/ou juvenis. Esse contexto corrobora as análises desenvolvidas por Shaw (2007) quando explicita que, em grande medida, o trabalho vinculado ao treinamento para a competição está associado à masculinidade, enquanto o ensino de habilidades esportivas voltadas para um caráter mais pedagógico vincula-se à feminilidade. Essas representações histo-

Movimento, Porto Alegre, v. 16, n. 01, p. 245-267, janeiro/março de 2010. 
ricamente têm produzido e reafirmado as assimetrias entre mulheres e homens no esporte.

Embora algumas das entrevistadas tenham participado como atletas em competições internacionais, inclusive nos Jogos Olímpicos, nenhuma delas atuou como treinadora de equipes de alto rendimento. Esse parece ser um espaço reservado aos homens, seja porque muitas mulheres não ousam lutar por ele, seja pelo fato de não atingirem os níveis de técnica, conhecimento e experiência necessários para fazê-lo. Embora não existam impedimentos escritos, tampouco legislações que impeçam as mulheres de ascender na carreira desportiva, algumas barreiras, ainda que invisíveis, dificultam tal transposição (PFISTER; RADTKE, 2007).

Segundo as entrevistadas, o acesso das mulheres ao treinamento das equipes de alto nível em Portugal caracteriza-se ainda como um obstáculo a ser transposto, dado que são os homens aqueles que são convidados para treinar as equipes. Assim que um deles se destaca, imediatamente é requisitado para treinar uma equipe masculina, lugar privilegiado em que se têm as melhores condições de trabalho e os melhores salários. Outra situação de desigualdade apontada pelas mulheres refere-se à desvalorização do esporte feminino quando comparado ao masculino e à posição secundária ocupada por elas na organização esportiva. Os excertos abaixo enunciam essas questões.

Ele começou no feminino, a certa altura ele conseguiu pelo que ele fez no feminino, reconheceram qualidade e foi convidado para o masculino, é um técnico habilitado mesmo e tem nível 4 de futsal, é professor de educação física e queria mais alguma coisa e ele não podia crescer dentro do feminino. Então o que é que acontece? Os treinadores mais qualificados fogem para o masculino. (Atleta e treinadora de futsal).

Houve uma altura que eu fui convidada para ser directora executiva do clube, era só jogadora nessa altura e tinha a escola de desporto e fui convidada para ser directora executiva do clube, mas mantinha as mesmas funções. Ou seja, ganhava a mesma coisa que na escola de desporto mas tinha muitas mais funções, e havia um outro sujeito que iria ser director

Movimento, Porto Alegre, v. 16, n. 01, p. 245-267, janeiro/março de 2010. 


\begin{abstract}
executivo, que era um sujeito que já lá estava há muitos anos, e a idade era um posto naquela altura. E nós tínhamos as funções equiparadas e eles propuseram que eu continuava com 80 contos por mês e ele ganhava 200 e qualquer coisa. (Ex-atleta, ex-treinadora e coordenadora de handebol).
\end{abstract}

As entrevistas apontam, ainda, que as diferenças entre os homens e as mulheres são evidentes não só nos clubes, como também nas Federações, que investem mais nas equipes masculinas do que nas femininas. Esse desequilíbrio tem produzido um movimento circular e difícil de ser rompido. Em outras palavras: maior investimento nas equipes/atletas masculinas/os possibilita melhores resultados, o que, por sua vez, atrai visibilidade na mídia, chamando a atenção de patrocinadores; estes, então, investem mais dinheiro nas equipes e/ou atletas, que assim têm melhores condições de treino e recebem os melhores salários. Enfim, são inúmeros os fatores que, uma vez reunidos, favorecem os homens no sistema esportivo português. Nas palavras de uma das entrevistadas:

\begin{abstract}
Se houvesse condições no feminino como há no masculino de certeza que elas investiam muito mais, porque eu conheço muito boas atletas que deixaram de jogar porque simplesmente têm que investir na profissão ou nos estudos...e depois os treinadores é a mesma coisa...os melhores treinadores, quem é que quer andar no feminino que anda com as bolas às costas. (Ex-atleta, ex-treinadora e coordenadora de handebol).
\end{abstract}

Nas suas narrativas, as mulheres destacaram que o escasso reconhecimento profissional não acontece somente em relação aos baixos salários que recebem na maioria das vezes, mas também aparece na diferenciação dos valores dos prêmios conquistados em diferentes modalidades e níveis esportivos. Ao analisar essa diferenciação, Santos (2001) afirma que, nesse caso, há uma violação dos direitos de igualdade inscritos na própria Constituição portuguesa e também reclamados na Declaração de Brighton. Apoiando-se nessa evidência, sugere que seja implementada, na sociedade portuguesa, uma "ação positiva" em favor de mulheres que, mesmo diante de condições adversas, atingem reconhecimento internacional tal qual a equipe masculina.

Movimento, Porto Alegre, v. 16, n. 01, p. 245-267, janeiro/março de 2010. 
Ao colocar em funcionamento ações dessa natureza, a autora acredita que se estariam corrigindo séculos de desigualdades. Embora essa sugestão possa produzir controvérsias, vale ressaltar que sua emergência se dá exatamente pela existência de uma profunda desigualdade nas condições de treinamento e trabalho de homens e mulheres no esporte, principalmente nos recursos que são aplicados em favor de uns e de outras. Dificuldades como essas têm inviabilizado a permanência de muitas mulheres no campo esportivo, que, diante de condições tão adversas, abandonam esse espaço para buscar melhores condições de trabalho, reconhecimento profissional e remuneração compatível com a sua função em outras áreas.

Além desses aspectos, as entrevistadas mencionaram que a estreita ligação do esporte com a juventude, o casamento e a decisão de apostar numa vida familiar em que o esporte não tem lugar, bem como a dificuldade para conciliar estudo com os treinamentos e a baixa remuneração, também influenciam nas decisões das mulheres de permanecerem ou abandonarem esse campo profissional. Ribeiro (2006, p. 114) afirma que ainda incidem sobre as mulheres no esporte "menor valor dos prêmios desportivos ou a ausência de subsídios/vencimentos para as mulheres atletas, ou piores ordenados para as treinadoras quando comparados com os dos seus colegas".

O esporte é um campo extremamente hierarquizado e masculinizado. Sobretudo, é caracterizado por profundas desigualdades de gênero e a mulher é a principal penalizada. Apesar desse amplo conjunto de assimetrias vividas pelas mulheres no esporte, emergem novas possibilidades no horizonte - possibilidades de as mulheres serem sujeitos de suas próprias posições e conquistas, pois percebem que, nesse jogo de poderes, o esporte é um território em construção, razão pela qual lutam para dele participarem ativamente e, por que não, conquistá-lo!

\section{ENTRE RESISTÊNCIAS E SUGESTÕES DE MELHORIAS NO ESPORTE}

Apesar de a análise das entrevistas apontar de forma recorrente para situações assimétricas entre homens e mulheres, no âmbito do esporte, de um modo geral, as entrevistadas não se posicionaram como

Movimento, Porto Alegre, v. 16, n. 01, p. 245-267, janeiro/março de 2010. 
vítimas de um sistema que está marcadamente dominado pelos homens. Nas suas narrativas, emergiram estratégias particulares de resistência, voltadas para conquistar espaços ou assegurar os que ocupam. Resistência é entendida aqui a partir da teorização de Michel Foucault (2005, p. 91), sobretudo, quando afirma que "onde há poder há resistência". Esta, ao emergir, produz deslocamentos, rompimentos e mudanças que acenam para transformações nos modos de produzir e constituir o esporte; acima de tudo, abre novas possibilidades nas relações entre homens e mulheres nesse campo.

Considerando o pressuposto de que as experiências de homens e mulheres estão ancoradas em vivências anteriores, concordamos com Markula (2005, p. 5) quando sugere que as resistências das mulheres às situações de opressão estão diretamente conectadas às "estruturas específicas das suas identidades de gênero", que são constituídas em consonância com as diferentes instâncias sociais. Nesse sentido, acolhemos falas de algumas entrevistadas que apontavam ser a sociedade portuguesa ainda tradicional, o que, de certa maneira, dificultava ainda mais as suas inserções no esporte. Ao rejeitarem a posição de vítimas, essas mulheres assumem os riscos e as ousadias de traçarem os seus próprios caminhos, como vemos abaixo:

[E perguntavam] [...] a sério, jogas hóquei? Ai, um desporto tão violento para uma menina! Mas é, sempre assim, é constantemente. Porque é uma modalidade em que as pessoas acham que há muita agressividade, muita dureza, e não veem isso feminino. (Atleta e treinadora de hóquei sobre patins).

Ouço falas, mas são brincadeiras, ou melhor, eu quero acreditar que são brincadeiras. Para eles, o homem já é aquele machão e garanhão que não se importa de ouvir nomes, e a mulher tem que ficar sensibilizada quando the chamam nomes. Eu não fico, nem tenho que ficar! É muito engraçado, juro-te, há situações em que uma pessoa está ali e dá vontade de rir! E sendo mulher e sabendo que há poucas, ainda mais gozo te dá, quer dizer, a assistência pode tentar eliminar cada vez mais as poucas mulheres que há no desporto, comigo não consegue. (Ex-atleta, ex-treinadora e árbitra de hóquei sobre patins).

Movimento, Porto Alegre, v. 16, n. 01, p. 245-267, janeiro/março de 2010. 
Por causa de nós vivermos ainda num mundo machista, às vezes as mulheres, por natureza e por questões culturais, não sentem aquela motivação em que consigam fazê-lo e depois, se calhar, não querem arriscar, dar aquele passo não tendo confiança nelas próprias. Não arriscam dar aquele primeiro passo e realmente conseguindo mostrar [...] nós somos capazes, então, nós não somos diferentes de ninguém. (Ex-atleta de natação e dirigente de basquetebol).

Notamos, ainda, nessas narrativas, que não há menção a grandes rompimentos ou profundas transformações, mas sim pequenas resistências espargidas no cotidiano dessas mulheres, ou seja: dar um passo em direção ao desconhecido, ousar naquilo que faz, manter-se firme em suas decisões, fazer-se ouvir em reuniões das Federações e clubes, ignorar ofensas, trabalhar mais do que muitos homens, fazer da discriminação um estímulo para a superação. Essas são, entre outras tantas, estratégias encontradas pelas mulheres para resistirem às constantes pressões à sua permanência no esporte. Foucault (2005) lembra-nos de que dificilmente acontecem "grandes rupturas radicais", verdadeiras revoluções de valores, de comportamentos e da própria vida dos indivíduos; o mais comum é encontrarmos as pequenas resistências que se mostram possíveis e necessárias naquele momento em particular, de acordo com suas condições de possibilidade.

Nas entrevistas, oito mulheres mencionaram algum momento que consideraram de resistência, o que não implica afirmar que as outras entrevistadas não as produzam em suas vidas. Talvez, no momento da entrevista, tenha-lhes escapado à lembrança. O reconhecimento das desigualdades é um dos fatores que impulsionaram a luta por melhores condições e valorização do seu trabalho e pela ampliação da sua participação em distintas esferas do esporte. As entrevistadas assinalaram que as suas batalhas, antes de tudo, são pessoais e, posteriormente, assumem a esfera pública e coletiva:

E de facto é verdade, as pessoas é que não se propõe às coisas. Eu propus-me, e as pessoas convidaramme, e eu enfrento os desafios, eu mesma me proponho aos desafios, porque não vejo diferenças. É obvio que existem alguns tipos de obstáculos que eu tenho que enfrentar e que os rapazes não têm, mas eu estou

Movimento, Porto Alegre, v. 16, n. 01, p. 245-267, janeiro/março de 2010. 
disposta a isso, estou disposta a ir à luta por eles.
Eu acredito naquilo que faço e acredito que toda a
competência cria o seu espaço. (Atleta e treinadora de futsal e futebol).

Agora, em termos do mundo da natação, no início olhavam-nos (duas dirigentes) como um bicho, dois seres estranhos, porque era um mundo muito de homens, treinadores, dirigentes. Mulheres éramos as primeiras, depois logo duas! Ainda vêem aos pares! (risos). As mulheres estão aqui a começar a entrar. (Ex-atleta de atletismo e dirigente de natação).

Resistir num território habitualmente não declinado no feminino produziu efeitos no âmbito das representações de gênero associadas ao esporte. Ao ampliarem sua inserção no esporte, as mulheres deslocaram representações que naturalizavam esse campo como um território onde a masculinidade se comprova, fraturando essa noção e borrando essas fronteiras. Embora seja senso comum considerar que o esporte não é mais um espaço exclusivamente masculino, ainda está longe de ser um território pleno de igualdades de oportunidades. Nesse sentido, é necessário reconhecer que as lutas femininas no âmbito do esporte são constantes e que os enfrentamentos são diários, dadas as desiguais relações de gênero que nele existem. Por tal razão, apenas o fato de as mulheres permanecerem no esporte já denota uma ação de resistência. Nota-se que algumas barreiras foram ultrapassadas, porém ainda muito há para se fazer.

Nessa direção, as entrevistadas sugerem ações que acreditam serem imprescindíveis para a ampliação da inserção e participação das mulheres nos vários níveis do esporte em Portugal; dentre as mais recorrentes, figuram: exigir que os clubes esportivos invistam também na formação esportiva de meninas; incentivar jogos educativos entre meninos e meninas, principalmente nos escalões infantis e juvenis; acompanhar e incentivar a longa permanência das meninas no esporte; investir maciçamente na ampliação das oportunidades de prática esportiva para todas as mulheres; incentivar o aperfeiçoamento profissional das mulheres, promovendo cursos de arbitragem, treinamento e gerenciamento esportivo e acompanhando os problemas vividos por elas nessas situações profissionais; incentivar a presença da mulher

Movimento, Porto Alegre, v. 16, n. 01, p. 245-267, janeiro/março de 2010. 
em equipes de arbitragem de todas as modalidades esportivas; incentivar mulheres a almejarem o treinamento de equipes de alto nível, tanto masculinas quanto femininas; reconhecer os esforços de muitas mulheres para vencer as barreiras estabelecidas no esporte; reclamar que a mídia amplie espaços de visibilidade de diversas modalidades esportivas e não somente do futebol e investir na visibilidade feminina em diferentes funções e esferas esportivas. Diante de tais possibilidades, elas acreditam que, assim: "Começava a criar igualdade entre homem e a mulher." (Ex-atleta e treinadora de hóquei sobre patins).

\section{CONSIDERAÇõES FINAIS}

Atentas ao trabalho que ainda está por se fazer, as mulheres apontaram a urgência de transformar o esporte em um espaço mais receptivo a relações de gênero mais igualitárias, o que, de certo modo, sinaliza que "a retórica da igualdade", tão focada em diversos níveis na Comunidade Europeia, ainda é algo que está muito distante de se efetivar. No que diz respeito ao esporte, Portugal tem se mostrado integrado no cenário das reivindicações que buscam ampliar a inserção feminina em diversos espaços e níveis esportivos, acenando com investimentos em projetos em que a preocupação com as mulheres assume um importante lugar. Entretanto, deseja-se que essas possibilidades saiam do papel e sejam implementadas, pois as assimetrias permanecem as mesmas há três décadas. $\mathrm{O}$ estudo aponta que investimentos reduzidos no esporte feminino, estrutura precária, salários e prêmios inferiores aos dos homens e pouca visibilidade midiática continuam a caracterizar as relações desiguais entre homens e mulheres no esporte. Entretanto, cada vez mais mulheres têm decidido investir profissionalmente no esporte. Apesar de todas as dificuldades, elas criam estratégias direcionadas à ampliação de suas funções e, assim, abrem espaços para uma longínqua permanência no campo esportivo.

O estudo também assinalou que muitas mulheres estão rejeitando a posição de vítimas em um espaço em que a presença masculina é marcante, para assumir uma atitude de resistência, perseverando nos lugares ocupados e levando adiante seus objetivos. Elas acreditam que as dificuldades que aparecem no esporte nada mais são do que desa-

Movimento, Porto Alegre, v. 16, n. 01, p. 245-267, janeiro/março de 2010. 
fios às suas vidas, os quais se manifestam dispostas a enfrentar. Ao sugerir mudanças na condução do esporte nacional, essas mulheres, mais uma vez, reafirmam as suas posições e desejam que as políticas públicas privilegiem a ampliação do acesso das mulheres ao esporte, oferecendo melhores condições para alongar a sua permanência nesse campo e investindo na profissionalização em todas as esferas e níveis esportivos. Por fim, esta pesquisa apontou que o reconhecimento das desigualdades é uma condição central para mobilizar ações que busquem privilegiar a igualdade de oportunidades entre homens e mulheres no esporte.

Movimento, Porto Alegre, v. 16, n. 01, p. 245-267, janeiro/março de 2010. 

Paths followed by women in sports in Portugal:
asymmetries, resistances and possibilities
Abstract: This research has been based upon the
theoretical field of Gender Studies. Twenty-one female
athletes and former athletes that perform technical and
managerial functions in the area of sports in Portugal
have been interviewed. Three meaning units have emerged.
The analysis of these units has allowed the identification
of developments in widening women's participation in
sports, even though women have to both diversify their
functions and accept work conditions that differ from
those available to men. Rejecting the position of victims,
the women interviewed have converted those asymmetries
into challenges and have also suggested actions to
encourage, widen and consolidate female participation
in all levels of sports.
Keywords: Women. Sports. Gender identity. Women,
working.

Trayectorias de mujeres en el deporte en Portugal: asimetrías, resistencias y posiblidades Resumen: Fundamentada en el aporte teórico de los estudios de género, esta investigación se efectivo a través de la realización de entrevistas con 21 mujeres atletas y ex-atletas actuantes en las funciones técnicas y directivas en el deporte de Portugal. Emergieron tres unidades de significados cuya análisis permite identificar un avanzo en la ampliación de la participación de las mujeres en el campo deportivo, aún que, para que se mantenga, sea necesario que las mujeres diversifiquen funciones y acepten condiciones de trabajo diferenciadas de aquellas ofrecidas a los hombres. Rechazando la posición de victimas, las entrevistadas transforman las asimetrías en desafios y sugieren acciones para incentivar, ampliar y consolidar la participación femenina en todas las esferas de competencia deportiva.

Palabras clave: Mujeres. Deporte. Identidad de género. Trabajo de mujeres.

\section{REFERÊNCIAS}

CARVALHO, Maria J.; CRUZ, Isabel. Mulheres e desporto: declarações e recomendações internacionais. Lisboa: Associação Portuguesa Mulheres e Desporto, 2007.

CRUZ, Isabel; SILVA, Paula; BOTELHO GOMES, Paula. Deusas e guerreiras dos Jogos Olímpicos. Porto, 2006.

Movimento, Porto Alegre, v. 16, n. 01, p. 245-267, janeiro/março de 2010. 
CRUZ, Isabel. Afinal, o que comemoramos. Ex aequo, Lisboa, n. 4, p. 7-11, 2001.

CRUZ, Isabel. Poderosas ou sexys: imagens das atletas nos médias. In: AMÂNCIO, Lígia; et al. (Org.). O longo caminho das mulheres: feminismos 80 anos depois. Lisboa: Dom Quixote, 2007.

FISCHER, Rosa M. B. Escrita acadêmica: arte de assinar o que se lê. In: COSTA, Marisa V.; BUJES, Maria Isabel. E. (Org.). Caminhos investigativos III: riscos e possibilidades de pesquisar nas fronteiras. Rio de Janeiro: DP\&A, 2005.

FASTING, Kari. Treinar: uma prática sexualmente diferenciada. Ex aequo, Lisboa, n. 4, p. 87-101, 2001.

FOUCAULT, Michel. História da sexualidade: Rio de Janeiro: Graal, v. 1.: A vontade de saber, 2005

GASKEL, Gaston. Entrevistas individuais e grupais. In: BAUER, Martin. W.; GASKELL, George (Org.). Pesquisa qualitativa com texto, imagem e som. Petrópolis: Vozes, 2000

GOMES, Euza. A participação das mulheres na gestão do esporte brasileiro: desafios e perspectivas. 2006. Tese (Doutorado) - Curso de Educação Física, Universidade Gama Filho, Rio de Janeiro, 2006.

GRAÇA, Odete. A participação das mulheres nos diferentes aspectos da dinâmica desportiva. Horizonte, São Paulo, v.21, n.122, mar./abr. 2006.

HALL, Ann. How should we theorize gender in the context of sport. In: SABO, Donald; MESSNER, Michel (Org.). Sport, men, and the gender order: critical feminist perspectives. Champaing: Human Kinetics, 1990.

KELLE, Udo. Análise com auxílio de computador: codifixação e indexação. In: BAUER, Martin W.; GASKELL, George. (Org.). Pesquisa qualitativa com texto, imagem e som. Petrópolis: Vozes, 2000.

MARKULA, Pirkko. Introduction. In: MARKULA, Pirkko. (Org.). Feminist sport studies: sharing experiences of joy and pain. New York: Sunny, 2005.

MARIVOÉT, Salomé. O género e o desporto: hábitos e tendências. Ex aequo, Lisboa, n. 4 , p. 115-132, 2001.

MARIVOÉT, Salomé. Assimetrias na participação desportiva: os casos de Portugal e Espanha no contexto europeu. Movimento, Porto Alegre, v.9, n.2, p. 53-70, maio/ ago. 2003.

MOURÃO, Ludmila. Exclusão e inserção da mulher brasileira em atividades físicas e esportivas. In: SIMÕES, Antonio C. (Org.). Mulheres e esporte: mitos e verdades. São Paulo: Manole, 2003.

MOURÃO, Ludmila; GOMES, Euza M. Mulheres na administração esportiva brasileira: uma trajetória em curso. In: SIMÕES, Antonio C.; KNIJNIK, Jorge. D. (Org.) O mundo

Movimento, Porto Alegre, v. 16, n. 01, p. 245-267, janeiro/março de 2010. 
psicossocial da mulher no esporte: comportamento, gênero, desempenho. São Paulo: Aleph, 2004

MOLINA NETO, Vicente. Etnografia: uma opção metodológica para alguns problemas de investigação no âmbito da Educação Física. In: MOLINA NETO, Vicente; TRIVIÑOS, Augusto N. S. (Org.). A pesquisa qualitativa na Educação Física. Porto Alegre: Editora da Universidade, 1999.

OLIVEIRA, Gabriela. Representações sociais de mulheres técnicas sobre o comando de equipes esportivas de rendimento. 2002. 125 f. Dissertação (Mestrado) - Programa de Pós-Graduação em Educação Física, Universidade Gama Filho, Rio de Janeiro, 2002.

PATTON, Michael Quinn. Qualitative research \& evaluation methods. 3. ed. London: Sage, 2002

PINTO, Teresa. Educação e políticas para a igualdade em Portugal: balanço e retrospectiva. In: AMÂNCIO, Ligia; et al. (Org.). O longo caminho das mulheres: feminismos 80 anos depois. Lisboa: Dom Quixote, 2007.

PFISTER, Gertrud; RADTKE, Sabine. Mulheres Tomando a Liderança ou mulheres tomando a liderança nas organizações esportivas alemãs. Movimento, Porto Alegre, v.13, n. 2, p. 77-90, maio/ago. 2007.

PFISTER, Gertrud; HARTMANN-TEWS, Ilse. Women and sport in comparative and international perspectives: issues, aims and theoretical approaches. In: PFISTER, Gertrud; HARTMANN-TEWS, Ilse. (Orgs.) SPORT and women: social issues in international perspective. New York: Routledge, 2003.

PFISTER, Gertrud. Líderes femininas em organizações esportivas: tendências mundiais. Movimento, Porto Alegre, v.9, n.2, p. 53-70, maio/ago. 2003.

RIBEIRO, João V. dos Santos. Queremos jogar: o acesso de raparigas ao desporto federado na área metropolitana de Lisboa. Dissertação (Mestrado em Estudos sobre Mulheres) - Lisboa: Universidade Aberta, 2006.

SANTOS, Madalena. A desporto igual, prémio igual! Ex aequo, Porto, p. 103-112, n. 4 2001.

SILVA, Paula; CARVALHO, Maria José. Da penumbra à luminosidade: recortes dos últimos 100 anos da participação feminina desportiva portuguesa. Ex aequo, Porto, n.4, p. 75-85, 2001.

SILVA, Paula; BOTELHO-GOMES, Paula; QUEIRÓS, Paula. Educação Física, Desporto e Género: o caminho percorrido na Faculdade de Desporto da Universidade do Porto (Portugal). Movimento, Porto Alegre, v. 12, n. 1, p. 31-58, jan./abr. 2006.

SHAW, Sally. Gender in sport management. A contemporary picture and alternative futures. In: AITCHISON, Cara C. (Org.). Sport \& gender identities: masculinities, femininities and sexualities. New York: Routledge, 2007. p.74-89.

Movimento, Porto Alegre, v. 16, n. 01, p. 245-267, janeiro/março de 2010. 
TRIVIÑOS, Augusto. Introdução à pesquisa em ciências sociais. São Paulo: Atlas, 1987.

Pesquisa financiada pela CAPES.

Recebido em: 30.04 .2008

Aprovado em: 25.11.2008

Movimento, Porto Alegre, v. 16, n. 01, p. 245-267, janeiro/março de 2010. 